\section{Estrategias de construcción y de difusión del patrimonio de la ciudad de Grasse (Francia)}

\author{
Chloé Rosati-Marzetti ${ }^{1}$ \\ 0000-0003-0447-7239 \\ Université Côte d'Azur (Niza), Francia
}

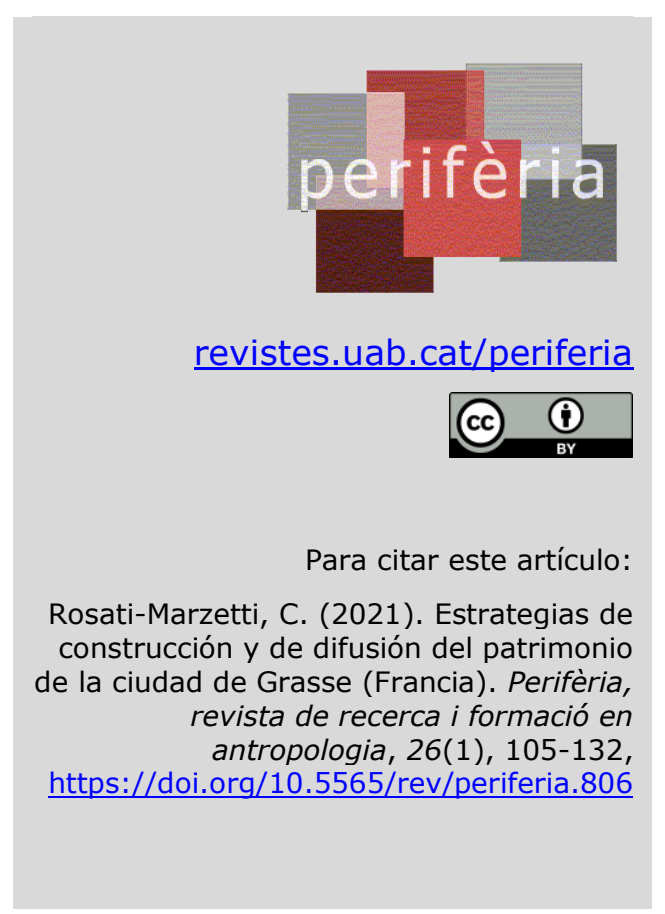

\title{
Resumen
}

El patrimonio es el espejo de la cultura que lo produce. Desde un punto de vista antropológico, la elaboración de mecanismos identitarios anclados en monumentos y en paisajes pueden ser deconstruidos para poner en evidencia el impacto del patrimonio cultural en la vida de sus habitantes. Este estudio, con base en la antropología de proximidad y realizado en la ciudad de Grasse (Francia), demuestra cómo es utilizado el patrimonio en la creación de identidad local y cómo puede impactar en los campos sociales, culturales, económicos y políticos. El patrimonio es empleado aquí para entender estrategias identitarias $y$, además, sirve de punto de referencia y de marcador local. Finalmente, sostenemos en este texto que legitima un orden establecido, permitiendo la difusión y expresión de la identidad así fijada.

Palabras clave: Antropología; Turismo; Identidad local; Patrimonio Cultural; Transmisión.

Abstract: Cultural heritage's construction and diffusion policy: the example of the city of Grasse (France)

From an anthropological point of view, the elaboration of identity mechanisms (rooted in monuments and landscapes) can be deconstructed in order to understand the

\footnotetext{
${ }^{1}$ Contacto: Chloé Rosati-Marzetti - chloe.rosati@gmail.com
} 
impact of cultural heritage upon its inhabitants' lives. This study, based on the French city of Grasse, demonstrates how heritage is used in the creation of local identity and how it can impact the social, cultural, economic and political fields. Heritage is used here to understand identity strategies. It is established as a point of reference and local marker. Finally, one can see how it legitimates a social order and validates a local identity.

Keywords: Anthropology; Tourism; Local identity; Cultural Heritage Transmission.

\section{Introducción}

Según el antropólogo francés Henri-Pierre Jeudy, "la identidad cultural viene para colmar las incapacidades de la identidad social", (Jeudy, 2008, p.46)2. Es decir, que la identidad cultural, anclada en el patrimonio, permite congregar a los individuos sobre un sitio, por muy diferentes que sean. El patrimonio puede así ser utilizado como un "remedio" para los "disturbios" identitarios. Cuando la identidad social está desfalleciendo, la identidad cultural puede tomar el relevo, y reúne a los individuos alrededor de un marco reconocible incluso por las personas externas al propio grupo, como los turistas.

Abordaremos este fenómeno estudiando la identidad cultural a través del patrimonio de una ciudad, es decir, los objetos, en sentido amplio, que generan una identidad. Entre estos objetos se encuentran los monumentos edificados, las plazas, los objetosrecuerdos, los carteles publicitarios, las señales de tráfico, las fotografías, las postales, las tradiciones, las fiestas locales, la ordenación urbana, etc. En breve, entenderemos el patrimonio como todo lo que participa en crear un "espíritu del lugar", es decir, todo lo que contribuye dando al sitio un carácter único. El espíritu del lugar sería pues una identidad que se habría definido e imaginado en el curso de los siglos con arreglo a la historia social y económica de la ciudad (Prado, 2010, p.126). Sería la imagen fantaseada que se tendría, es decir, un a priori con el cual el turista quiere confrontarse en el momento de su viaje.

${ }^{2}$ Las traducciones de las citas son de la autora. 
Los objetos que constituyen el patrimonio cultural tienen un sitio importante en la vida de un grupo social porque transmiten una identidad. Es decir, el patrimonio edificado, pero también el espíritu que este patrimonio insufla al sitio, lo tangible y lo intangible. De acuerdo a lo anterior, podemos argumentar que el patrimonio puede ser utilizado como un "remedio" a las confusiones identitarias.

El patrimonio urbano, tal como lo consideramos aquí, englobará monumentos, pero también las plazas, los carteles publicitarios, las señales de tráfico, la planificación urbana, en resumen, todo lo que participa en crear un "espíritu del lugar". Estos objetos, así como las instituciones que los administran y los valorizan, cuentan con gran importancia en la vida de un grupo social (Rosati-Marzetti, 2013). Su uso político, económico y cotidiano genera un sentimiento de pertenencia identitaria.

Tomemos el postulado de que el estudio del patrimonio cultural parece revelar las preocupaciones y orientaciones identitarias de una sociedad. El patrimonio es un producto cultural (Bruguière, 2006, p.10). Puede servir para informarnos sobre la sociedad que lo produce y que le da su sentido cotidiano. Sería tal el espejo de la cultura de una comunidad. De hecho, como objeto que transmite sentido, resulta pertinente utilizar el patrimonio para comprender y estudiar la identidad de un grupo. Supongamos que el patrimonio puede ser un recurso, una bandera identitaria para los habitantes de un lugar ¿Cómo puede congregar a un grupo social de individuos muy diferentes entre sí?

Desde un estudio antropológico llevado sobre la ciudad de Grasse (véase Imagen 1), este artículo quiere mostrar la importancia de la utilización del patrimonio en la creación de la identidad local. Veremos de qué manera las instituciones públicas, los profesionales del turismo y las entidades locales lo usan para valorizar un sitio y unir a los individuos que viven en este. Abordaremos también un regreso rápido sobre las nociones de memoria colectiva, de identidad y de paisaje; estas tres ideas están vinculadas en un contexto patrimonial. 


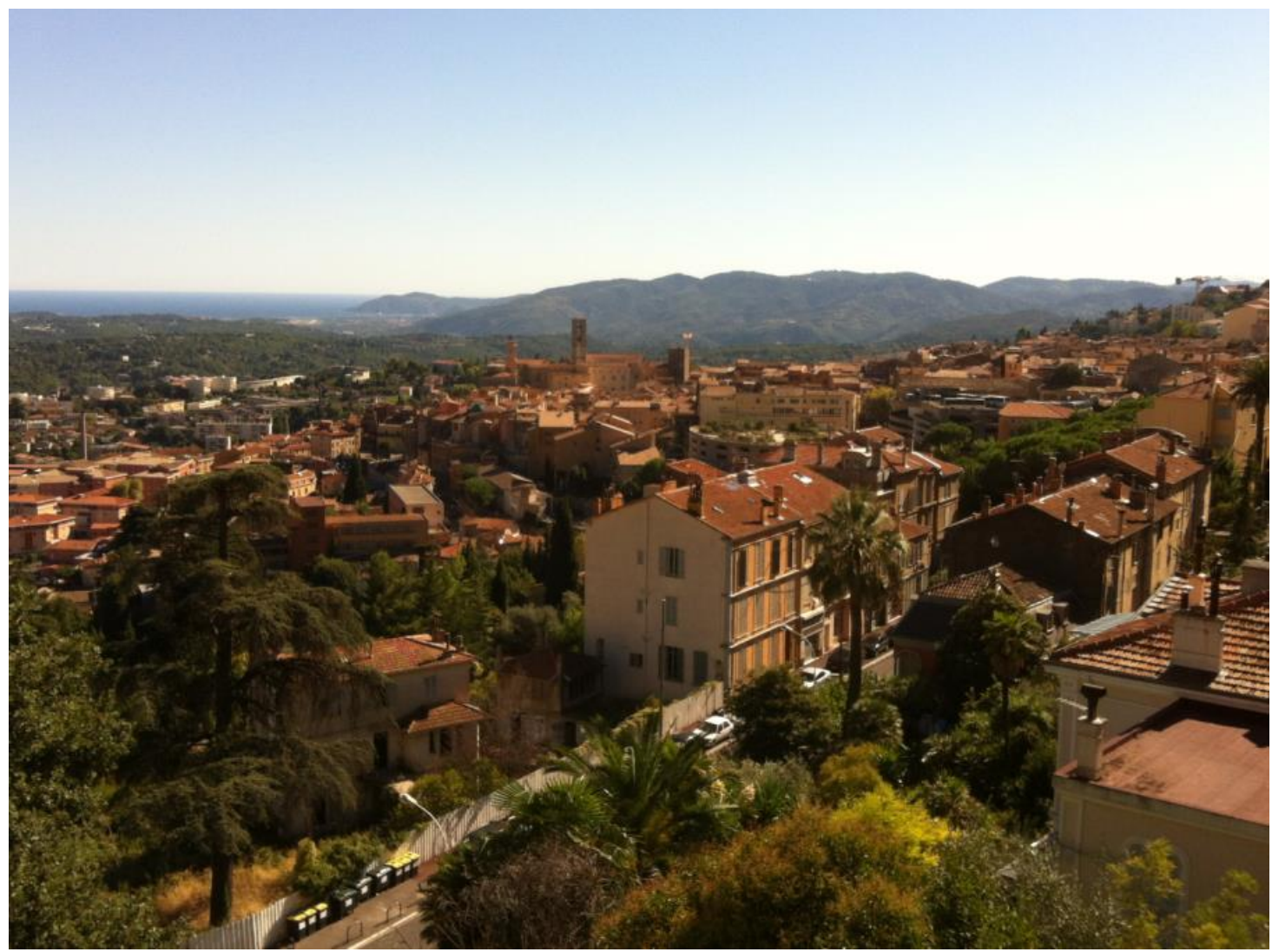

Imagen 1: La ciudad de Grasse, (c) Chloé Rosati-Marzetti, 2018.

\section{Situación actual}

\section{Métodos y metodología}

Este artículo es el resultado de una investigación etnográfica dentro de un marco temporal amplio. El trabajo de campo, iniciado en 2009, fue al principio un trabajo universitario (tesis doctoral) y posteriormente continuado en estudios de postdoctorado. La última investigación de campo fue durante la primavera de 2021. Para este trabajo se aplicó la vía inductiva. La metodología se compone de observaciones, participantes y no participantes, de entrevistas etnográficas, conversaciones individuales y colectivas, formales e informales. A la observación participante y a las entrevistas, se agrega lo que Jean-Pierre Olivier de Sardan Ilama la vigilancia de rutina (2000, p.44) que consiste en prestar atención a las interacciones cotidianas y lo que Colette Pétonnet (1982) llama la observación flotante que consiste en dejarse absorber por el campo. 
Para comprender el discurso de los habitantes de la ciudad, realicé varias entrevistas semi-dirigidas in situ a turistas y a otros habitantes de la ciudad; realicé varias sesiones de observación participante y no-participante visitando distintos lugares de la ciudad, acompañada de estos informantes; y finalmente, estudié los registros de debates y actas del ayuntamiento para comprender las decisiones municipales en la planificación urbana (desde 1980 hasta 2016).

A efectos de este trabajo, fueron entrevistados comerciantes, funcionarios, perfumistas, representantes municipales, grassois ${ }^{3}$ de adopción o personas que crecieron en Grasse y emigraron. Los turistas fueron entrevistados en el centro histórico de la cuidad, en las calles durante las visitas. Las otras personas fueron entrevistadas en sus puestos de trabajo o en sus casas. Las personas que emigraron de Grasse fueron entrevistadas en las casas de su familia en periodos de visita.

Para comprender lo que se dice a los turistas he estudiado los mensajes del patrimonio, el discurso expositivo, participado en las visitas del centro histórico de la cuidad y trabajado sobre archivos, iconografía turística, guías, sitios web, literatura (novelas, biografías, monografías, literatura académica), etc. De este modo, el trabajo permite configurar una doble visión de la ciudad: la opinión de los habitantes y la opinión de los turistas.

Es también importante para la comprensión del contexto añadir que la investigación se sitúa metodológicamente en el campo de la etnología de proximidad (Ségalen, 1989; Augé, 1999; Gullestad, Lien, y Melhuus, 2009 ; Monjaret, 2012), Ilamada también etnología at home. Por eso, fue necesario hacer una distanciación importante con el campo, hacer un cuestionamiento reflexivo permanente durante los cinco primeros años de este trabajo; hacer una "objetivación del sujeto de la objetivación" (Bourdieu, 2003, p.43). Es decir, el investigador debe objetivar su subjetividad. La participación del investigador "en un campo, previo a la investigación, puede también influir en la percepción de la realidad de la que se quiere dar cuenta" (Ouattara, 2004, p.1).

\footnotetext{
${ }^{3}$ Gentilicio de los habitantes de la Ciudad de Grasse.
} 


\section{Contexto teórico}

Esta investigación en antropología del patrimonio tiene como objetivo mostrar la relación entre el patrimonio local, la identidad de un grupo y el turismo, es decir, de la memoria colectiva y lo que mostramos de ella. La antropología del patrimonio ha sido ampliamente debatida dentro de la disciplina durante los últimos treinta años, aun así, nos parece importante comentar brevemente aquí los principales aspectos en el estudio de este campo.

La memoria constituye un elemento importante dentro las sociedades humanas. En efecto, "está en el principio de toda transmisión, es el cimiento de la cultura" (Candau, 2005, p.2). La memoria es una invención social (Halbwachs, 1950). Está estructurada por diferentes condiciones sociales y tradiciones específicas de los diferentes grupos. La memoria colectiva sería en realidad una memoria de grupo, una memoria social (Halbwachs, 1925); es decir, la memoria colectiva está modelada por la sociedad.

Un trabajo de utilización de la memoria colectiva permite legitimar acciones. La memoria colectiva es una visión del pasado, es "la transmisión de un recuerdo dentro de un pequeño grupo, un recuerdo que uno quiere tener en cuenta" (Finley, 1993, p.32-33). Los recuerdos creados constituirán, pues, una nueva cultura o permitirán actualizar una cultura en retroceso.

Usar el pasado permite crear identidades que están modeladas por una referencia permanente a los recursos de memoria seleccionados (es decir, elegimos lo que deseamos). "No hay memoria individual que no sea orientada socialmente. El individuo usa sus recuerdos con la ayuda de los contextos de la memoria social" (Halbwachs, 1925).

Según Claude Lévi-Strauss, "una sociedad no puede mantenerse a sí misma, si no está apegada incondicionalmente a valores. Y para ser incondicionales, deben hacer un trabajo sensible que los proteja del trabajo de zapa de la razón" (1988, p.121). La elaboración de una memoria colectiva, en la que se encuentra todo el grupo afectado, da unidad y homogeneidad a este grupo. Permite a los miembros del grupo hablar con una sola voz. Entonces, la construcción de la memoria y los recuerdos compartidos crean identidades. La identidad debe ser compartida y transmitida dentro del grupo. Para eso es necesario encontrar vectores de transmisión eficaz. La 
memoria y la identidad se transmiten gracias a la comunicación: en particular, gracias al patrimonio (Rosati-Marzetti, 2013). Los individuos moldean las memorias colectivas para que coincidan con la visión que el grupo desea dar (Halbwachs, 1950). Es lo que permitirá a un grupo, a una nación o a un territorio, construir una identidad satisfactoria para la mayor cantidad de gente posible (Nora, 1984).

Trabajar sobre las prácticas de la memoria, como procesos sociales, da luces sobre las políticas de memoria vinculadas a los grupos. La sociedad produce una deformación de la memoria individual para constituir una memoria colectiva y la memoria compartida dentro de un grupo se ve en símbolos, valores y emblemas. "La memoria, en efecto, es un marco más que un contenido, una apuesta siempre disponible, un conjunto de estrategias, un ser, que vale menos por lo que es que por lo que hacemos de él" (Nora, 1984, p.VIII).

Es la memoria colectiva la que permite crear identidades colectivas. Los individuos se encuentran dentro de un grupo que comparte una memoria común, una identidad colectiva y entonces un patrimonio, el grupo puede presentarse a los turistas a través de monumentos capaces de realzarlo y magnificarlo, pero también puede representarse a sí mismo como un grupo coherente, compartiendo los mismos valores, el mismo territorio, referencias, etc. Desde el trabajo de campo, vemos que la identidad local se transmite según los usos que los individuos pueden hacer de ella. "La identidad no es sólo una producción de enraizamiento, del lugar, es también una producción de movimiento, de adaptación al movimiento y de trascendencia" (Marié, 2004, p.159). Estos elementos patrimoniales dan legibilidad y orientan el discurso en el tiempo, de acuerdo con las necesidades del grupo.

"El patrimonio no tiene nada que ver, ontológicamente, con el arte, la historia, la rareza, la autenticidad, la antigüedad, la excepcionalidad dada por los expertos, [es] sobre todo un asunto de adhesión y reconocimiento" (Hottin, 2017, p.148-149). La antropología del patrimonio "se pregunta por lo que tiene sentido y que es íntimo para los actores y, a veces, se aleja de las grandes narrativas patrimoniales de la nación, transmitidas por los historiadores" (Isnart, 2016, p.7). En efecto, se tratará aquí de la microhistoria y no de lo que está difundido en la memoria colectiva.

Nos esforzaremos por presentar este patrimonio local a través del ejemplo de la construcción patrimonial, es decir, monumentos, conocimiento, ideas, todo lo que 
está pensado como una característica del lugar. Aquellos actúan como lo que los geógrafos llaman geosímbolos (Bonnemaison, 2000) o haut-lieu (Débarbieux, 2013) que atraen los turistas. Los estudios han demostrado que el patrimonio y el territorio están intrínsecamente vinculados (Di Méo, 1994; Marié, 2004).

La antropología del patrimonio se ha interesado por el vínculo entre patrimonio y memoria o identidad colectiva, a lo que se le agrega una tercera entrada: el turismo. Gracias a un patrimonio atractivo, el turismo tiene efectivamente un impacto significativo en la economía (Lavoie, 2014 p.140).

A través del ejemplo etnográfico de la ciudad de Grasse que sigue, veremos cómo se construye y con qué finalidad. Lo que nos interesa especialmente aquí es que "la cuestión, ya no reside en la búsqueda de orígenes, cuya prueba serían las marcas de objetos o prácticas, sino que reside más bien en el análisis de los procesos de apropiación y transmisión entre herederos y donantes" de este patrimonio (Le Coq, Léonard, Dartiguenave, Quimbert, Quentel, 2019, p.192).

"El patrimonio es una construcción resultante de una compleja interacción entre tres polos más o menos independientes: el mundo científico (...); el poder político en un sistema democrático (...); el poder económico (...)" (Bonnot, 2002, p.159-160). Por patrimonio cultural nos referimos a todo lo que está producido por un grupo, una comunidad (tangible o intangible). El objeto tangible o intangible se convierte en patrimonio según como la gente lo mire; es una creación que permite dar respuesta a cualquier necesidad del momento (Skounti, 2010). La patrimonialización de un objeto permite mostrar el valor del mensaje.

El patrimonio envía un mensaje en el tiempo que salta a la vista y que está aquí para ser visto; está consagrado a transmitir mensajes a las generaciones futuras (transmisión de una historia, de la memoria de una sociedad pasada, de individuos). Es un patrimonio común, y es por esto que tiene un carácter identitario importante, que refuerza las identidades locales (Jeudy, 2008). La patrimonialización produce una mirada íntimamente relacionada en relación con la percepción de la historia del lugar (Heinich, 2009, p.252).

El patrimonio contribuye a la construcción del territorio y por lo tanto de la identidad local. Es decir, que esta identidad es algo en lo que los individuos se reconocen y se establecen como comunidad, compartiendo los mismos valores, normas sociales, 
herencia, etc. (Lavoie, 2014). La comunidad se representa como un grupo cultural: un conjunto de individuos que se identifican con un patrimonio que tiene sentido.

En el marco del patrimonio, la identidad hacer nacer un sentimiento de pertenencia al sitio, aunque los habitantes sean muy diferentes entre sí. El patrimonio puede utilizarse como un remedio para problemas identitarios: cuando la identidad social está fallando, la identidad cultural puede funcionar, en tanto en cuanto, reúne a las personas en torno a un punto de vista reconocido también por las personas que no son miembros del grupo. El patrimonio y la identidad se alimentan mutuamente.

Estos sentimientos de pertenencia son inseparables del territorio (o paisaje) donde se nació. Y el paisaje es por definición cultural (Cauquelin, 2000). En el sentido común, la noción de paisaje se refiere a un territorio donde la naturaleza no deja paso a los humanos. Sin embargo, el territorio está fuertemente culturalizado. Los geógrafos fueron los primeros en insistir en su carácter antropizado. Trabajado constantemente y moldeado por las preocupaciones contemporáneas, el paisaje cambia con los tiempos y necesidades. Así, el paisaje se considera un "artificio" estético (Cauquelin, 2000, p.82) creado por la mano del hombre para satisfacer sus necesidades y expectativas. La dimensión cultural está íntimamente ligada a la percepción que los seres humanos tienen de este paisaje. Cada paisaje depende de la percepción que tenemos de él y se interpreta según el uso que los individuos le dan (Berque, 1994, p.17).

La manera en que miramos el paisaje es el resultado de una evolución del pensamiento a través la historia. Esta "invención" del paisaje se construyó socialmente gracias a un cambio en las representaciones del hombre y su relación con la naturaleza (Tobelem, 1992, p.57). La imagen del paisaje se construye según las necesidades del momento y según la identidad que queremos transmitir, por eso todo paisaje es cultural por definición; se crea según nuestra percepción, nuestras concepciones, nuestro a priori cultural (Cauquelin, 2000).

El concepto de "paisaje cultural" fue desarrollado por la UNESCO en 1972. El artículo I de la Convención sobre la Protección del Patrimonio Mundial, Cultural y Natural dice que los paisajes culturales son el resultado de fenómenos naturales y construcciones humanas (UNESCO, 2005, p.48). Esta noción se refiere aquí a un conjunto de monumentos y lugares que marcan una ciudad, le permiten distinguirse y que, en 
ocasiones, se convierten en sus emblemas. El paisaje cultural se forma esencialmente a partir de algunos monumentos históricos. La elección de los monumentos se refiere a aquellos que son juzgados estéticamente "bellos" o que tienen un valor simbólico importante.

Los monumentos y las partes de un paisaje son elegidos por su poder de atracción, la orientación cultural e identitaria que pueden dar. Se deben tomar decisiones para mantener pura la inteligibilidad del mensaje, para no desdibujar su comprensión y mantener una identidad que sea clara y fuerte. El paisaje es, por tanto, la marca de los individuos que lo configuran. A un nivel más largo, cada grupo humano hace de su paisaje un objeto que se supone se le parece como la mayor parte de los habitantes y en el que se reconoce. Entonces, el paisaje actúa como un signo de reconocimiento del grupo con el cuál éste puede definirse o realzarse.

Para el turismo, el paisaje cultural ha sido fabricado para crear la atracción, como escena de representaciones simbólicas. Y de este modo se configura el territorio, para provocar el deseo, incluso el exotismo, de acuerdo con las necesidades económicas y turísticas. Pensemos aquí que el paisaje cultural escenifica la idea de lo "local" y que corresponden a representaciones que resultan de la demanda turística (Rosati-Marzetti, 2014). Entonces, los individuos se posicionan dentro de un grupo que comparte una memoria común y una identidad colectiva. En efecto, la construcción del paisaje (y por tanto del patrimonio) es vivida y sentida por los nativos.

Este fenómeno de construcción compartida de la identidad local y de patrimonio (Rosati-Marzetti, 2013) puede abordarse estudiando la identidad cultural a través del patrimonio urbano, es decir, a través de objetos que crean unidad. El espíritu del lugar corresponde entonces a una identidad que se habría ido definiendo y forjando a lo largo de los siglos según la historia social y económica de la ciudad. Sería la imagen fantaseada que tendríamos, un supuesto que se transmite muchas veces en el mundo del turismo y con el que se supone que debe enfrentarse el viajero al visitar un sitio.

Para ilustrar y comprender eso vamos a ver como esta co-construcción funciona en el sitio turístico de la ciudad de Grasse, mundialmente reconocida por sus perfumerías. 


\section{Ilustración etnográfica: el ejemplo de Grasse (Francia)}

\section{Presentación de la ciudad}

Grasse se sitúa al sur de Francia (Imagen 2), al oeste del departamento de los Alpes-

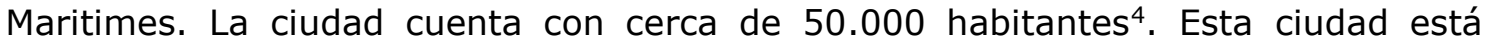
construida entre el mar Mediterráneo y los Alpes. Su topografía varía desde los 100 a los 1000 metros de altitud. Ofrece así una diversidad ecológica sobre un territorio limitado $(44 \mathrm{~km})$. La vieja-ciudad está construida en el costado de una colina (cerca de 300 metros de altitud) y domina una vasta llanura.

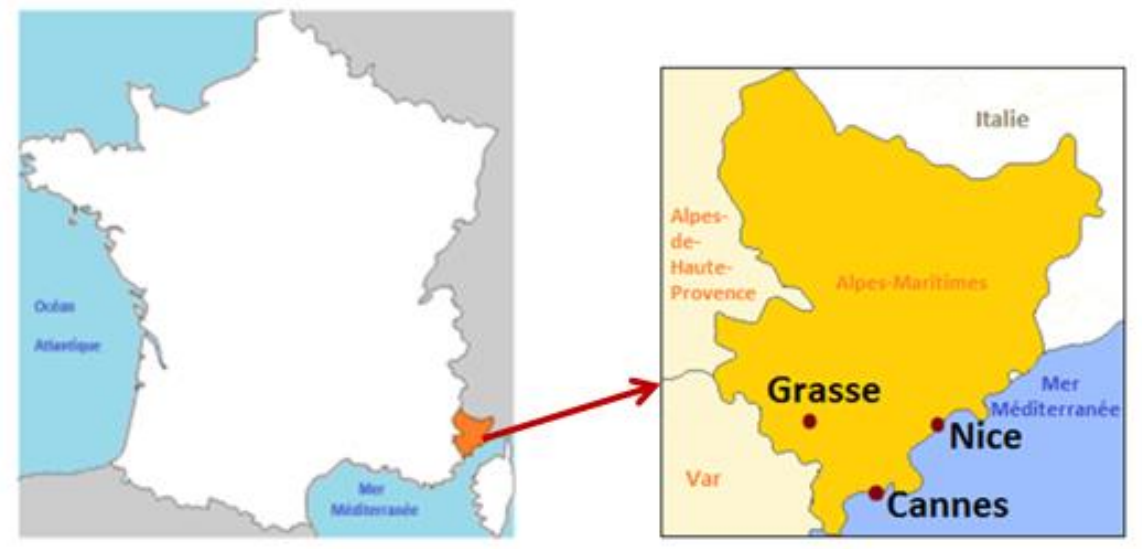

Imagen 2: localización de Grasse. (C) Chloé Rosati-Marzetti, 2020.

\section{Historia}

La historia de la ciudad se sitúa a partir del siglo XIII, con la instalación del obispado en la ciudad, aunque el lugar muestra signos de ocupación desde el Neolítico. Durante su historia, Grasse tuvo un papel administrativo importante. Fue, por ejemplo, el sitio del tribunal revolucionario durante la Revolución Francesa y, luego, en el momento

\footnotetext{
${ }^{4}$ Poblaciones legales 2017 del municipio, según el INSEE (Instituto Nacional de Estadística y de Estudios Económicos).
} 
del Directorio (de 1789 a 1799). Hoy se encuentra la subprefectura del departamento.

Grasse, ciudad industrial y comercial, fundó su reputación sobre la explotación y la transformación de sus recursos naturales para la industria del perfume. Antes de la perfumería, la cuidad fue reconocida por la curtiduría ${ }^{5}$, practicada en el Medievo, desde el siglo XIII hasta el XV, aproximadamente. Luego los impuestos sobre los pieles transformara la curtiduría en guantería-perfumería ${ }^{6}$ y por la jabonería (actividad auxiliar de la perfumería) en el Renacimiento (finales del siglo XV y siglo XVI). La geografía, el clima y la presencia de agua desempeñaron un papel preponderante en el desarrollo de estas actividades.

Hoy Grasse es considerada y llamada por sus ediles como la "Capital mundial de los Perfumes". Fue el sitio de descubrimientos y de avances industriales importantes en este campo. Este artículo de lujo que es el perfume, dio a la ciudad su fama y su reputación internacional.

\section{Un clima favorable}

El clima de tipo mediterráneo es relativamente dulce, aunque las "heladas blancas" son frecuentes en invierno. Las grandes variaciones de altitud sobre el territorio de Grasse ofrecen una multitud de terrenos propicios a la plantación y al cultivo de diversas plantas ${ }^{7}$. Es gracias a este clima particular, que se le califica comúnmente como "microclima excepcional". La perfumería encontró allí un suelo propicio para su desarrollo. Las plantas cultivadas vienen del mundo entero, y más particularmente

\footnotetext{
${ }^{5}$ Transformación de piel de vaca.

${ }^{6}$ Utilización de piel de oveja, más pequeñas y delgadas (menos impuestos). Los guantes perfumados tenían buena reputación durante el Renacimiento. La curtiduría - con la utilización de las plantas aromáticas utilizadas para el tanino - y la guantería dan lugar a la perfumería. Fue el comienzo de esta nueva actividad de perfumería en el siglo XVIII de manera artesanal y después industrial desde el medio del siglo XIX.

7 Las plantas aromáticas como el tomillo o la violeta (que busca el fresco) en altitud, y las plantas delicadas como la rosa o el jazmín en las llanuras.
} 
de oriente, como es el caso de la rosa centifolia, producción muy famosa de la ciudad $^{8}$, importada inicialmente de Turquía.

Este clima no solo fue benéfico para las plantas para perfumes, también abrió la ciudad al turismo. Desde el final del siglo XIX, la ciudad de Grasse está considerada como una estación "climatérica": lugar de cura para las enfermedades respiratorias. Después, la connotación medicinal fue evacuada y Grasse se hizo estación climática. Así, la industria turística de la ciudad se constituyó al inicio sobre su paisaje natural, y después orienta su actividad turística hacia la artesanía e industria del perfume, con lo que los turistas vienen en masa para visitar las fábricas de perfumes. Estas son verdaderas fábricas-museos ${ }^{9}$ recreadas para los visitantes o fábricas aún en actividad. La ciudad pasa de un turismo paisajístico (de la naturaleza, del clima) a un turismo patrimonial (con monumentos y experiencias, técnicas, know-how).

\section{Una localización simbólica}

Sin embargo, el abundante turismo no se debe solamente a esta destreza local particular que es la perfumería y se explica también por la posición geográfica que ocupa la ciudad. La ciudad de Grasse pertenece a la Provenza, región geográfica muy famosa que se extiende de este a oeste, del río Var al Ródano.

La Provenza disfruta de un clima clemente, mientras que Francia ofrece una gran diversidad de suelos y climas muy diferentes. Simbólicamente, esta región es asociada con el sol, la naturaleza, las cigarras, la lavanda y los productos del terruño (como las aceitunas, el aceite de oliva y el vino rosado, por ejemplo). El departamento de los Alpes-Maritimes tiene frontera con Italia y se encuentra a caballo entre la Provenza oriental y el antiguo condado de Niza (anexionada a Francia en 1860). Grasse casi se sitúa en una frontera conceptual invisible, en posición liminal. Por eso, no duda en proclamarse "Puerta de Provenza Oriental", que será la última ciudad importante antes de Niza y su región. En consecuencia, la creación del departamento de los Alpes-Maritimes supone un aliciente de regionalismo para los

\footnotetext{
${ }^{8}$ Este rosa entra, por ejemplo, en la fabricación de perfumes prestigiosos y mundialmente conocidos.

${ }^{9} \mathrm{O}$ "perfumerías turísticas", según el término empleado por la Oficina de turismo.
} 
"grassois" que se reivindican entonces cada vez más provenzales, puesto que se sienten desarraigados de esta región geográfica (Decaux 1964, Boyer 2002).

Es, precisamente, este hecho de sentirse desarraigados lo que exacerba la identidad del grupo, aunque se expresa de formas muy variadas. Esta identidad va a relacionarse en lo sucesivo, y simbólicamente, con la sociedad a la cual pertenecía (aquí Provenza) construyéndose en oposición a la sociedad a la que fue incorporada tras su anexión. No es completamente lo que era antes pero no pertenece tampoco, según sus habitantes, al sitio al que fue asignada. El grupo se encuentra entonces en una frontera identitaria, un territorio limite (Van Gennep, 1909). Es también por esto que el patrimonio está construido aquí según una identidad doble (provenzal y perfumada).

El perfume da una singularidad a esta ciudad provenzal. Los fundamentos de la identidad de la ciudad, e indirectamente de sus habitantes que se reconocen en estas proposiciones identitarias, se distribuyen entre dos polos: los perfumes como una particularidad local reconocida mundialmente, y su adscripción a la Provenza en tanto que región turística muy apreciada. Esta identidad doble es visible, en el seno mismo de la ciudad, a través de los monumentos y de su entramado urbano. El patrimonio cultural de Grasse está orientado y dirigido a mostrar estas características.

\section{Construcción de patrimonio}

La ciudad de Grasse dispone de un patrimonio edificado que reconstituye su historia. Este patrimonio describe a la vez la provenzalidad de la ciudad y la perfumería. Estos dos polos de la identidad "grassoise" no están en oposición, lo que permite a la ciudad y a sus habitantes singularizarse en el seno de la Provenza. Por su situación liminar, entre Provenza y Costa Azul, algunos "grassois" se definen como fuertemente provenzales (Schor, 2007). Efectivamente, como están en una frontera, los sentimientos de pertenencia están exacerbados (Schipper, 2001 y Delfosse, 2001).

\section{Un patrimonio provenzal}

Los rastros de la pertenencia de Grasse a la Provenza se aprecia directamente en la topografía de la ciudad: pequeñas calles tortuosa (Imagen 3), callejones con pendientes, presencia de muchos puntos de aguas (fuentes y lavaderos), 
arquitectura de hoteles particulares y monumentos de $\operatorname{poder}^{10}$, etc. Ciertos monumentos importantes y característicos de las ciudades provenzales están presentes como, por ejemplo, la plaza mayor con su reloj (Imagen 4), los molinos de aceite, la torre llamada "Sarracena" (Imagen 5), el Curso"11.

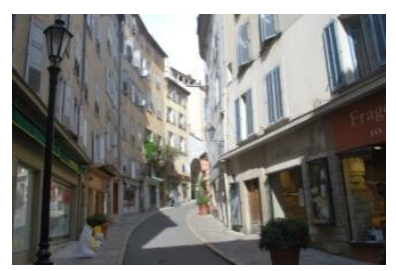

Imagen 3: Calle del centro histórico, Chloé Rosati-Marzetti, 2018.

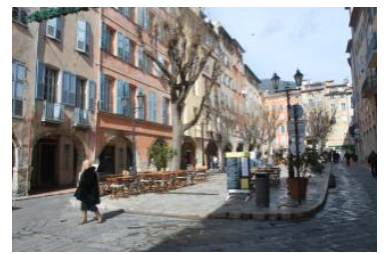

Imagen 4: La plaza mayor, (c) Chloé Rosati-Marzetti, 2018.

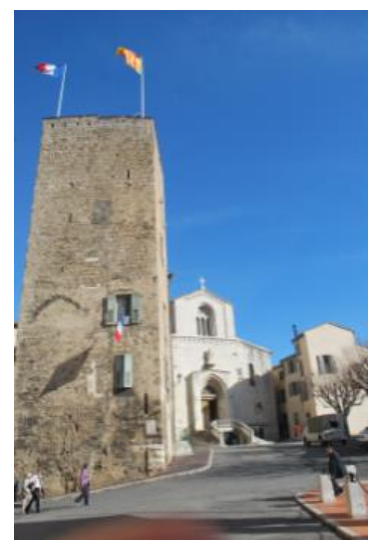

Imagen 5: La torre y la catedral. En la torre se ve la bandera francesa y la occitana, (c) Chloé Rosati-Marzetti, 2020.

\footnotetext{
${ }^{10}$ Por ejemplo el tríptico clásico: Tribunal-Gendarmería-Prisión. La Catedral y el Ayuntamiento (el antiguo palacio episcopal) testimonian un estilo arquitectónico "Romano" provenzal.

${ }^{11}$ Gran explanada para el paseo, a finales del siglo XIX y principios del siglo XX. Son, por ejemplo, las famosas explanadas de "La Croisette" en Cannes o "La Promenade des Anglais" en Niza.
} 
Para acentuar estos parámetros urbanos los políticos locales han empezado, hace más de una década, a reactivar el regionalismo con ciertos monumentos y encantos urbanos. En consecuencia, descubrimos en la ciudad la presencia de ornamentos como la bandera Occitana (a rayas doradas y rojas), la plantación de olivos, las señales bilingües ${ }^{12}$ a la entrada de la ciudad, etc. Encontramos información sobre la adopción de estas decisiones por parte de los políticos en los informes de los ayuntamientos. Estos documentos nos muestran la manera en que se constituyó una voluntad de puesta en escena identitaria.

Los profesionales del turismo señalan esta pertenencia regional a través de dos museos: uno público, el Museo de Arte y de Historia de Provenza (MAHP) ${ }^{13}$; y uno privado, el Museo Provenzal del Traje y de la Joya. Los vendedores de Grasse sacan provecho de esta visibilidad, para promover sus productos y dar una ilusión de autenticidad. Esta noción transmite una imagen de fabricación artesanal con respeto a las tradiciones, mostrando una connotación de producción local ancestral mientras que a menudo se trata de producción industrial proveniente de fuera del terruño "grassois". Responden a las esperanzas de los turistas que buscan objetos "típicamente locales".

Muchos restaurantes y tiendas utilizan nombres en dialecto local. Las tiendas de recuerdos presentan objetos a la efigie de cigarras, de madera de olivo, "indias"14, saquitos "de hierbas de Provenza", lavanda, "jabones de Marsella", ... Estos símbolos son visibles sobre las postales (Figuras 1 y 2 ) y ciertos carteles publicitarios.
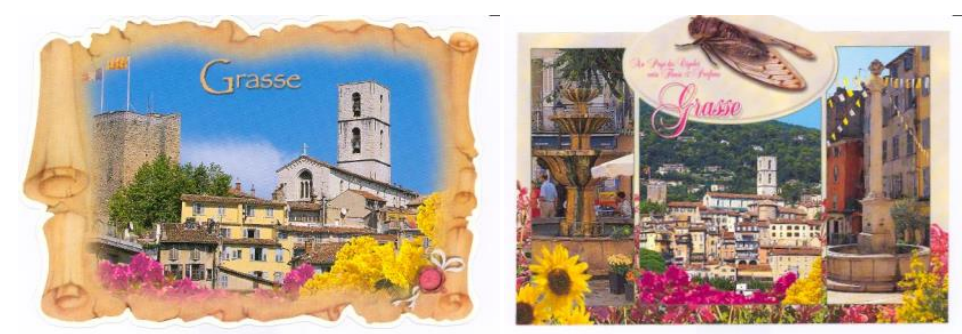

Figuras 1 y 2: postales que ilustran la provenzialidad, (C) Chloé Rosati-Marzetti, 2020, Colección personal.

\footnotetext{
12 Francés - provenzal.

13 Museo de historia local.

${ }^{14}$ Nombre dado a los tejidos provenzales con motivos florales.
} 


\section{Patrimonio de la perfumería}

En paralelo, el patrimonio relativo a la perfumería es omnipresente en la ciudad y es más evidente. Además del patrimonio provenzal, los poderes públicos dirigen el mobiliario urbano para que todo nos recuerde que estamos en la capital del perfume (Figuras 3 y 4 ).
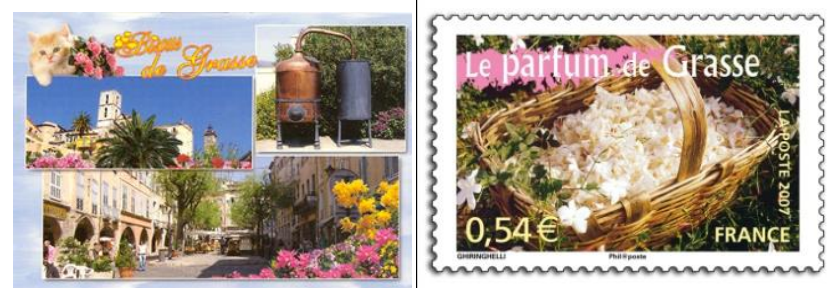

Figuras 3 y 4: postal ilustrando perfumes y sello "perfume de Grasse" con jazmín, @ Chloé Rosati-Marzetti, 2020, Colección personal.

Ciertas rotondas o lugares se atavían de símbolos de la perfumería: por ejemplo, alambiques (Imagen 6), frascos de perfumes (Imagen 7), esculturas alegóricas de la perfumería o del oficio de perfumista, etc.
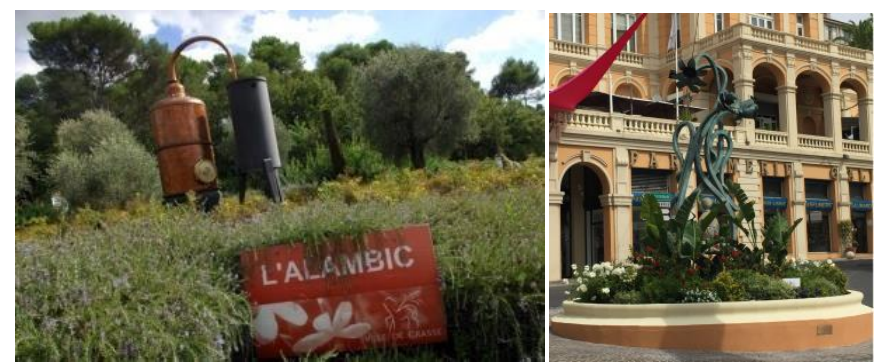

Imágenes 6 y 7: Rotonda con alambique y rotonda con frasco de perfume, (c) Chloé RosatiMarzetti, 2017 y 2021.

Las flores están muy presentes en el centro de la ciudad, alrededor del trayecto turístico diseñado por la municipalidad. Muchas calles tienen un nombre que remite a grandes familias locales, pioneras en la industria de la perfumería. Las tiendas de recuerdos (Imagen 8 ) abundan en perfumes, incienso, popurrí o jabones perfumados. 


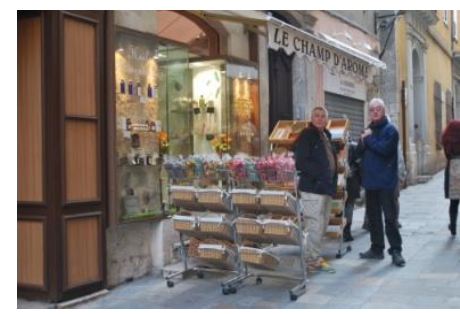

Imagen 8: Tienda de recuerdos "El campo de los aromas" con accesorios de perfume, Chloé Rosati-Marzetti, 2017.

Los poderes públicos están fuertemente implicados en la construcción y valorización de este patrimonio como lo demuestra la renovación del Museo Internacional de la Perfumería (MIP) y una inscripción del perfume al UNESCO. La mayoría de los monumentos valorizados hoy se vinculan con la perfumería. Hasta la Oficina municipal de turismo, presenta esencialmente el patrimonio industrial de la ciudad que es juzgado como el más representativo de la vida "grassoise". El MIP y las tres grandes fábricas-museos de la ciudad son protagonistas en los folletos y en la señalización urbana. Los profesionales del turismo y los políticos intentan presentar Grasse con un punto de vista que acentúa los perfumes. Si es necesario, lo desvían de lo que no tuvo relación con este anclaje industrial en el tiempo y el espacio.

\section{Puesta en escena de un patrimonio}

La validez y la credibilidad de este patrimonio están acentuadas por la publicidad hecha alrededor de estos lugares punteros. El papel de los museos no es despreciable tampoco puesto que dan un carácter científico y legítimo a esta creación de identidad. Todos los monumentos y las etiquetas de calidad turística lo acreditan.

Esta puesta en escena patrimonial da un sentimiento de unida a los habitantes y les singulariza sobre el territorio "grassois" frente a los territorios adyacentes. Todo esto contribuye, luchando contra el miedo a la uniformización (Bromberger y Morel, 2001). Esta manipulación magnifica la ciudad y la erige como la capital indiscutible del perfume. Se apoya en un imaginario fantaseado o embellecido que confirma un patrimonio cultural único a los turistas en búsqueda de autenticidad y de descubrimiento. 


\section{Estrategias de difusión y de incorporación}

Para que esta construcción sea eficaz es necesario que primero se haya validado e incorporado, pudiendo ser posteriormente difundida. Para transmitir su mensaje, el patrimonio manipulado debe estar anclado en el tiempo y convertirse en punto de referencia de la memoria colectiva. Así puede aparecer como auténtico y verídico.

\section{El papel de la producción documental turística}

Las guías turísticas constituyen un soporte de trabajo interesante. Ponen de manifiesto los elementos patrimoniales de moda en el curso del tiempo según las épocas y sus corrientes de pensamiento. También expresan este "espíritu" del lugar.

En cuanto a la ciudad de Grasse, es posible cubrir casi un siglo de turismo gracias a la "high-life"15 y a las guías turísticas ${ }^{16}$. Ocurre también con los carteles publicitarios. El estilo de los sujetos o la iconografía evoca también las preocupaciones de un período dado (Figuras 5 y 6 ). Tomemos el ejemplo de los personajes de colores pastel que pasean sobre los carteles de los años $1930^{17}$, período en que Grasse se sitúa como lugar de veraneo. Tenemos también carteles que muestran qué actividades podían desarrollarse en Grasse.

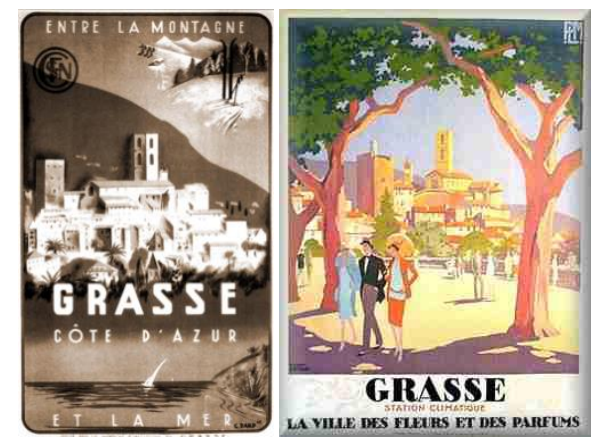

Figuras 5 y 6: Carteles publicitarios de los años 1930, Chloé Rosati-Marzetti, 2020, Colección personal.

\footnotetext{
${ }^{15}$ Guías de sociedad mundana. La burguesía inglesa, particularmente, estaba muy presente en la "Riviera" desde finales del XIX y principios del siglo XX.

${ }^{16}$ Esencialmente Michelin, Dunlop y Baedeker para la primera mitad del siglo XX.

${ }^{17}$ En Francia, el turismo se democratiza en esta época. Las primeras "vacaciones pagadas" en Francia datan de 1936.
} 
En cambio, en torno a 1900, sólo el paisaje está representado: montañas detrás y el mar en primero plano, encuadrando a la ciudad. Grasse fue un lugar de veraneo desde la segunda mitad del siglo XIX y hay mucha publicidad que promociona la ciudad, sobre todo desde la llegada del ferrocarril en 1890. Todos estos documentos vuelven a trazar más de un siglo de veraneo, y generan luces sobre el contexto de emergencia y de construcción del patrimonio cultural "grassois", aunque el fondo documental es menos surtido para ciertas épocas notamente de 1960 hasta 1980 porque carteles publicitarios, folletos turísticos, flyers o postales de este periodo no se conservaran en los archivos.

Los eslóganes utilizados por los publicistas para describir la ciudad también testimonian esta evolución. Así, al principio del siglo $\mathrm{XX}$, el eslogan "Entre mar y montaña" evoca la estación climática. El de los años 1980 "Puerta de Provenza Oriental", y más recientemente, el nuevo eslogan "Vivir la Costa Azul del interior" evoca la situación geográfica de la ciudad de Grasse e intenta sacar provecho del flujo turístico drenado por los atractivos de la Costa. En cuanto a ellos, los eslóganes de los años 1930 y 1990 - respectivamente "Ciudad de las flores y de los perfumes" y "Capital Mundial del Perfume"), hacen directamente referencia a la destreza local. Todas estas voluntades políticas de valorización del patrimonio sirven para orientar la construcción identitaria según las necesidades de una época.

\section{El espíritu del lugar}

Para delimitar lo que puede ser la identidad "grassoise", es también interesante el estudio de las novelas cuya acción se desarrolla en Grasse. Ciertamente transmiten una imagen novelada de la ciudad, pero que puede tener un impacto sobre la visión que la gente construye sobre la misma. Fue por ejemplo el caso de la adaptación cinematográfica, en 2006, del libro de Patrick Süskind, "El Perfume" (Süskind, 1988). Después de haberla visto, mucha gente fue a Grasse para descubrir este aspecto pintoresco de la ciudad medieval, de sus fábricas de perfumes y de sus campos de flores hasta perderse de vista, descritos en esta obra.

De hecho, en los años 90 y después antes de la inscripción à la UNESCO, el imaginario de la cuidad presentaba los campos de flores hasta donde alcanza la vista. El famoso 
serial televisado "En un gran viento de flores"18 (calificado como la "saga" del verano de 1996), donde se agregan romance y traiciones sobre un trasfondo de perfumerías y de campos de flores a perfumes, contribuyó también a transmitir esta idea de que Grasse es por excelencia "la ciudad de las flores y de los perfumes"19 (Imágenes 9 y 10).
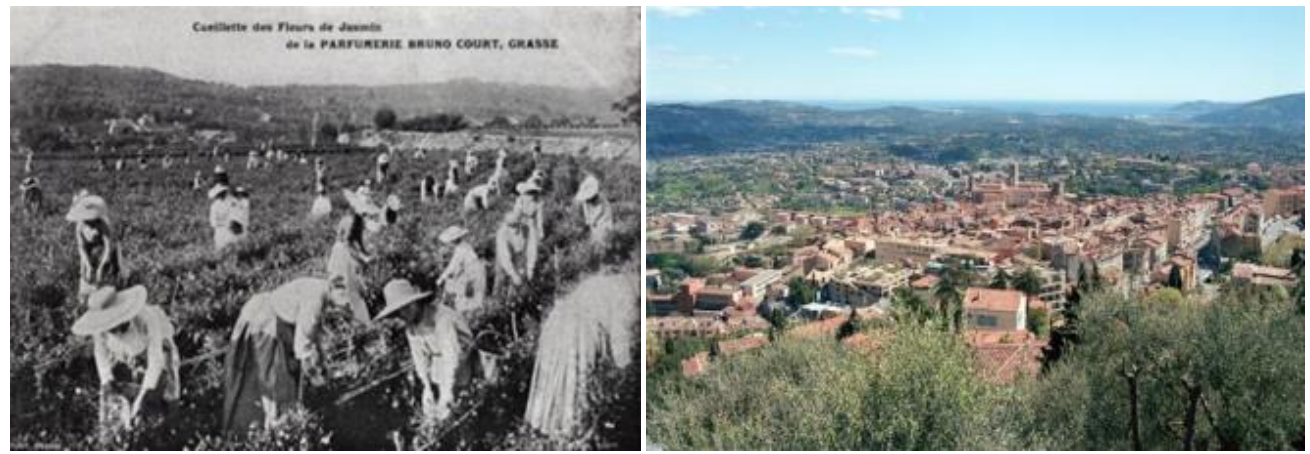

Imágenes 9 y 10: Ilanuras en los años 1940 (postal, archivas de Grasse) y llanuras ahora, Chloé Rosati-Marzetti, 2018, Colección personal.

Esto nos alumbra sobre la versión predominante de la identidad de la cuidad que flota en el curso de los siglos. Esta investigación sobre la construcción de una identidad local puede ser completada con la ayuda de los informes municipales. Estos documentos oficiales relatan las preocupaciones de los políticos locales en materia de valorización de patrimonio, muestran lo que ha sucedido en el curso de los años para hacer concordar la realidad con la imagen que la municipalidad desea transmitir. Se trata aquí de confirmar, mediante construcciones físicas, la mayoría de las veces, la imagen de "sí para sí" (para sentirse "grassois") y de "sí para otros" (para mostrarles a los turistas que somos "grassois" y lo que implica). Tanto los sitios web oficiales de la ciudad como los del Ayuntamiento, la Oficina de turismo, o los Museos de Grasse corroboran esta visión, a través de las presentaciones de lugares de la ciudad y, sobre todo, a través de las fotografías escogidas para ilustrar este "espíritu" de la ciudad.

\footnotetext{
18 En siete episodios.

${ }^{19}$ Eslogan utilizado desde los años 1930, particularmente sobre los carteles publicitarios y el cartel PLM (antigua Compañía de los ferrocarriles de París-Lyon- Mediterráneo, creado en 1857 y cerrado en 1938).
} 
Los museos también son un resumen de su historia, afirman y confirman la identidad colectiva de los habitantes. El estudio del discurso museístico, y la manera en que está difundido (particularmente por los escolares), nos informa sobre las orientaciones identitarias escogidas por los elegidos locales y muestra de qué manera esta identidad colectiva es transmitida a las nuevas generaciones. A través de los museos, los niños pueden apropiarse la identidad local y muestra una continuidad sobre el territorio.

Los museos difunden también la identidad a las turistas. Exposiciones temporales y publicaciones se organizan regularmente para poner de reloeve una particularidad del territorio, y demostrarle al público la legitimidad de la identidad colectiva.

\section{Conclusiones}

El patrimonio "grassois" está seleccionado para anclar una identidad local en el tiempo y el espacio. Se hace una herramienta de comunicación y de difusión de las ideas locales fuera del sitio mismo. Estudiar esta identidad por medio del patrimonio y "de-construir" el simbolismo de los monumentos "punteros" de un sitio actualiza las estrategias y los mecanismos de acentuación de un fenómeno de construcción local, dirigidos para promover una economía industrial y turística, y una política de desarrollo urbano.

El patrimonio está orientado a fines comerciales que genera el turismo. Se construye también con arreglo a las proyecciones turísticas y los estereotipos transmitidos por la literatura. Debe representar la vida imaginada para el lugar, para que su identidad se exporte más allá de sus fronteras. El patrimonio cultural se convierte en un medio para propagar ideas fuera de la ciudad de Grasse. Así, es un instrumento eficaz en la comunicación porque es inmediatamente visible sobre el territorio de Grasse. Grasse puede así proclamarse polo cultural pionero ${ }^{20}$ e ineludible en el dominio de la industria del perfume, guardián de una memoria colectiva única.

\footnotetext{
20 Recordemos que Francia produce el $40 \%$ de la producción mundial en materia de aromas y de perfumería, repartido entre Grasse y la región parisina. Hay también muchas filiales de empresas de Grasse en el extranjero.
} 
Poner en evidencia esta puesta en escena patrimonial permite comprender las estrategias identitarias. El patrimonio cultural es utilizado como un punto de referencia, un marcador local. Legitima un orden establecido y permite a la identidad fijada exportarse y difundirse, valida la búsqueda de reconocimiento social del grupo. Todas estas estrategias permiten la elaboración de un patrimonio cultural homogéneo identitariamente aceptable para los habitantes de Grasse. Debe también seducir a los visitantes. Con las guías turísticas, los sitios web, el MIP y, sobre todo, los objetosrecuerdos, la ciudad de Grasse resplandece y se exporta más allá de su territorio. En efecto, los objetos-recuerdos son un buen testigo, tanto para los "grassois" como para los turistas, de la aceptación y de la incorporación de la identidad propuesta conjuntamente por el poder público y los profesionales del turismo. Y el resultado de esta construcción se encuentra en la obtención de etiquetas, por el momento, Grasse es reconocida por su calidad patrimonial a nivel nacional, a través la etiqueta "País y Ciudad de Arte y de Historia".

El patrimonio desempeña un papel importante en la invención de la memoria de un lugar, es seleccionado para anclar una identidad local en el tiempo y el espacio. En efecto, como hemos visto y como lo subraya Pierre Nora, "la memoria del pasado no es la imagen fiel de este pasado" (Nora 1984, p.X). Está arreglada y orientada a menudo a fines identitarios y a veces a fines económicos, la memoria colectiva está depurada. Entonces, la memoria colectiva es "lo que tiene un valor para las personas y que los diferencia de los otros porque existe un recuerdo compartido. (...) Lleva la historia que se cuenta y que cuenta" (Halbwachs 1950, p.52).

Aferrarse a un pasado, aunque no sea fiel a la historia, permite vivir más fácilmente el presente y preparar una continuidad para el futuro. La creación de una memoria colectiva es necesaria para que los "individuos lleguen a compartir prácticas, representaciones, creencias, recuerdos, en una palabra, el sentido, produciendo así, en la sociedad considerada lo que se llama la cultura" (Candau 1998, p.3). Tenemos aquí un mecanismo de retroalimentación porque la memoria colectiva necesita del patrimonio para confirmarse y esta misma memoria es invocada para legitimar las acciones patrimoniales y la supuesta veracidad del patrimonio local.

Esta elaboración identitaria sirve para crear una imagen ventajosa y atractiva para hablar de los habitantes y de la cuidad. Podríamos decir que esto permite entonces seducir al "Otro" para generar turismo. Efectivamente, el turismo le transmite a la 
vez representaciones "a sí para sí", y representaciones "de sí para los otros". Es decir que "seducir al Otro" es la condición indispensable para el desarrollo y para la renovación perpetua del turismo. Así, las producciones comerciales elaboradas alrededor del patrimonio se transforman en vectores identitarios. El patrimonio desempeña un papel importante en la invención turística de un lugar y sobre la identidad que deseamos atribuirle. Tal como es utilizado hoy, se hace, según las palabras de Gérard Lenclud: "un pedazo de pasado tallado a las medidas del presente" (Lenclud, 1987, p.120).

Los objetos, creados, modelados, usados y rechazados por los humanos, constituyen por tanto un excelente método de acercamiento a los grupos humanos (Baudrillard, 1968, Julien y Rosselin, 2005). Dependiendo de nuestras necesidades puramente biológicas, reflejan nuestro sentido social y representan un medio de comunicación e intercambio dentro del grupo. También se muestran a elementos externos a ella, como reflejo de una identidad y un deseo de distinción (Warnier, 1999). Las estrategias humanas relativas a los objetos son innumerables y están estrechamente vinculadas a los contextos en los que se emplean (Leroi-Gourhan, 1964). Ya sean producciones locales o no, se sienten como tales, al igual que las imágenes de la ciudad utilizadas como escenografía de este marco identitaria (Rosati-Marzetti, 2013).

Aquí hemos considerado estos objetos como fundamentos y vectores de la "identidad" de Grasse. Se trata de resaltar lo que la ciudad de Grasse da a ver de ella a sus visitantes y lo que toman y aceptan como especificidad de esta aglomeración; sus habitantes y sus diversas producciones. La identidad así creada (adoptada a grandes rasgos por los habitantes) permite crear discurso, transmitir y mostrar valores $y$, por tanto, generar una memoria colectiva. Además, el turismo, al reunir alteridades, permitiría legitimar y reconocer el lugar.

Por tanto, la promoción de la identidad y el turismo puede pasar por la escenificación de la identidad local y de la memoria colectiva. La máxima consagración de esta presentación de la ciudad a las turistas se encuentra en la inclusión en la Lista Representativa del Patrimonio Cultural Inmaterial de la UNESCO, una etiqueta internacional, considerada como la máxima consagración del patrimonio y el turismo. 
El patrimonio se convierte en un títere, un estandarte de identidad para los habitantes de un lugar porque muestra el imaginario del lugar. Y es a través de la presentación de uno mismo y la visión que los turistas tienen de nosotros que podemos construir una identidad local. Esto permite unir dentro de un grupo social a individuos que son muy diferentes entre sí, pero que se adhieren a esta idea estereotipada de ciudad.

\section{Bibliografía}

Anónimo, (2005). Reunión de Expertos sobre Paisajes Culturales en el Caribe: Estrategias de identificación y salvaguardia, Santiago de Cuba, noviembre 7-10.

Augé, M. (1999). Le sens des autres, Paris : Fayard, Coll. Actualité de l'anthropologie. Baudrillard, J. (1968). Le système des objets, Paris: Gallimard, coll. Tel.

Bouju, J. (2002). Se dire Dogon. Usages et enjeux politiques de l'identité ethnique, Ethnologies comparées, n5, p. 1-17.

Bourdieu, P. (2003). L'objectivation participante, Actes de la recherche en sciences sociales, vol. 150, p.43-58.

Boyer, M. (2002). L'invention de la Côte d'Azur, L'hiver dans le Midi, Paris : éd. de l'aube, coll. Monde en cours, Série Essais.

Bruguière, J. (2006). Le rapprochement des notions de bien et de produit culturel. LEGICOM, n³6, p. 9-17.

Cachat, S., Chave, I. y Tornatore, J.-L. (2020). Patrimoine et territoire: une parenté conceptuelle en question, Les Cahiers du CFPCI, n॰7, $222 \mathrm{p}$.

Candau, J. (1998). Mémoire et identité, Paris: PUF, coll. Sociologie aujourd'hui.

Candau, J. (2005). Anthropologie de la mémoire, Paris: Armand Colin, coll. Cursus Sociologie.

Cauquelin, A. (2000). L'invention du paysage. Paris: PUF, coll. Quadrige, 180 p.

Davallon, J. (1992). Le musée est-il vraiment un média ?, Culture \& Musées, n², p. 99-123.

Débarbieux, B. (2013). Haut lieu. En Jacques Lévy, J. y Lussault, M. (org.), Dictionnaire de la géographie et de l'espace des sociétés, Paris : Belin. 
Decaux, A. (1964). Les Heures Brillantes de la Côte d'Azur, Paris: Presses Pocket.

Delfosse, C. (2001). Quand l'économie partage les sociétés. La frontière entre deux systèmes fromagers dans le département de Haute-Marne, en Bromberger, C. y Morel, A., Limites floues, frontières vives. Des variations culturelles en France et en Europe, Paris: MSH, Mission du patrimoine ethnologique, Coll. Ethnologie de la France, cahier 17.

Di Méo, G. (1994). Patrimoine et territoire, une parenté conceptuelle, Espaces et sociétés, no 78, p. 15-34.

Finley, M. (1993). Mythe, mémoire, histoire, Paris: Flammarion, coll. Nouvelle Bibliothèque Scientifique.

Gombault, A. (2014). Le marketing du patrimoine culturel. En Bourgeon-Renault, D., Debenedetti, S., Gombault, A. y Petr, C. (org.), Marketing de l'Art et de la Culture, Paris: Dunod.

Gullestad, M., Lien, M., Melhuus, M., (2009). Anthropologie "chez soi" et anthropologie « chez l'autre ». Une distinction à dépasser, Ethnologie Française, Vol. 38, p. 206-215.

Halbwachs, M. (1925). Les cadres sociaux de la mémoire, Paris : PUF, coll. Bibliothèque de philosophie contemporaine.

Halbwachs, M. (1950). La mémoire collective, Paris : PUF.

Heinich, N. (2009). La fabrique du patrimoine. De la cathédrale à la petite cuillère, Paris: MSH, coll. Ethnologie de la France.

Hottin, C. (2017). Présent et devenir du patrimoine culturel immatériel, Le Débat, n०194, p. 147-152.

Isnart, C. (2016). Anthropologie du patrimoine, Encyclopædia Universalis, p. 1-10.

Jeudy, P.-H. (2008). La machinerie patrimoniale, Paris: Circé.

Julien, M.-P. y Rosselin, C. (2005). La culture matérielle, Paris: La Découverte, coll. Repères. 
Lavoie, M. (2014). Les enjeux de la patrimonialisation dans la gestion du développement économique : un cadre conceptuel, Sociétés, $n^{\circ} 125$, p. 137151.

Le Coq, S., Léonard, J., Dartiguenave, J.-Y., Quimbert, Ch. y Quentel, J.-C., (2019). Patrimoine et transmission, Tétralogiques, n²4, p. 167-193.

Lenclud, G. (1987). La tradition n'est plus ce qu'elle était... Sur les notions de tradition et de société traditionnelle en ethnologie, Terrain, n9, p. 110-123.

Leroi-Gourhan, A. (1964). Le geste et la parole, Paris: Albin-Michel, coll. Sciences aujourd'hui.

Lévi-Strauss, C. (1988). De près et de loin, Paris: Odile Jacob.

Marié, M. (2004). Penser le local comme lieu de l'universel, Ethnologie française, Vol. 34, p.157-160.

Monjaret, A. (2012). Pour une anthropologie de Paris, Ethnologie française, Vol. 42, p. $413-417$.

Nora, P. (1984). Lieux de mémoire, Paris: Gallimard, Tome I, La République.

Olivier de Sardan, J.-P. (2000). Le « je » méthodologique. Implication et explicitation dans l'enquête de terrain, Revue française de sociologie, $n^{\circ} 41(3)$, p. 417-445.

Ouattara, F. (2004). Une étrange familiarité, Cahiers d'études africaines, n¹75, p. 1-19.

Pétonnet, C. (1982). L'observation flottante. L'exemple d'un cimetière parisien, $L^{\prime}$ Homme, 22, $n^{\circ} 4$, p. 37-47.

Pitte, J.-R. (2010). Le génie des lieux, Paris: CNRS-Editions.

Prado, P. (2010). Lieux et délieux, Communications, Autour du lieu, n87, p.121-127.

Rauch, A. (2002). Le tourisme ou la construction de l'étrangeté, Ethnologie française, Vol. 32, p. 389-392.

Rosati-Marzetti, C. (2013). L'identité d'une ville à travers ses artefacts. Grasse de 1860 à nos jours. Etude de la co-construction d'un imaginaire touristique et d'une identité locale (tesis doctoral, Université de Nice-Sophia Antipolis). 
Rosati-Marzetti, C. (2014). Les enjeux du paysage culturel grassois, entre tourisme et identité : Paysage, patrimoine et identité, Paysages, CTHS, p. 189-199.

Ségalen, M. (1989). L'autre et le semblable. Regards sur l'ethnologie des sociétés contemporaines, Paris : Presses du CNRS, coll. CNRS plus.

Schippers, T. (2001). Trouver la bonne distance, en Bromberger, C. y Morel, A., Limites floues, frontières vives. Des variations culturelles en France et en Europe, Paris: MSH, Mission du patrimoine ethnologique, Coll. Ethnologie de la France, cahier 17.

Schor, R. (2007). Les parlementaires des Alpes-Maritimes et l'implantation locale au $\mathrm{XX}$ siècle », Paris: L'Harmattan, Parlement[s], Revue d'histoire politique, $\mathrm{n}^{\circ}$ 7 , p. $35-46$

Skounti, A. (2010). De la patrimonialisation: comment et quand les choses deviennent-elles des patrimoines ?, Hesperis-Tamuda, p. 19-34.

Süskind, P. (1988). Le parfum. Histoire d'un meurtrier, Paris: Livre de poche, coll. Littérature et documents.

Tobelem, J.-M. (1992). De l'approche marketing dans les musées, Culture \& Musées, n०2, p. $49-70$.

Van Gennep, A. (1909). Les rites de passage. Etude systématique des rites. De la porte du seuil, de l'hospitalité, de l'adoption, de la grossesse et de l'accouchement, de la naissance, de l'enfance, de la puberté, de l'initiation, de l'ordination, du couronnement, des fiançailles et du mariage, des funérailles, des saisons, etc., Paris: éd. Emile Nourry.

Warnier, J.-P. (1999). Construire la culture matérielle: L'homme qui pensait avec ses doigts. Paris: PUF.

Agradecimiento: Doy las gracias à Sophie Álvarez-Vieitez para su ayuda en español. 